\title{
Prognostic value of IGF-IR expression in bone and soft tissue sarcomas: comments on a meta-analysis by Liang et al
}

This article was published in the following Dove Press journal:

OncoTargets and Therapy

5 April 2016

Number of times this article has been viewed

Chao $\mathrm{Tu}^{\prime}$

Jieyu $\mathrm{He}^{2}$

Zhihong $\mathrm{Li}^{3}$

'Department of Geriatric Surgery, ${ }^{2}$ Department of Geriatrics,

${ }^{3}$ Department of Orthopedics and Institute of Senile and Aging Diseases,

The Second Xiangya Hospital of Central South University, Changsha, People's Republic of China
Correspondence: Zhihong $\mathrm{Li}$ Department of Orthopedics and Institute of Senile and Aging Diseases, The Second Xiangya Hospital of Central South University, People's Middle Road, Changsha, 4I00II, Hunan Province, People's Republic of China $\mathrm{Tel} / \mathrm{fax}+8673185295167$ Email xyeyy_geri@I26.com

\section{Dear editor}

Recently, we read with deep interest a meta-analysis by Liang et al entitled "Prognostic value of IGF-1R expression in bone and soft tissue sarcomas: a meta-analysis" published in OncoTargets and Therapy. In this article, the investigators systematically reviewed the trials on the effects of IGF-1R expression in various bone and soft tissue sarcomas (BSTSs) and performed a meta-analysis. They reached an important conclusion that elevated IGF-1R expression was associated with poor overall survival in BSTS patients. Furthermore, subgroup analysis revealed that IGF-1R level was negatively correlated with prognosis in osteosarcoma but not significantly associated with Ewing's sarcoma. ${ }^{1}$ We sincerely appreciate the tremendous effort made by the investigators. Nevertheless, before their results can be accepted, some worthwhile issues need to be addressed first.

1. To begin with, there are quite a few deficiencies in the literature research. First, only two electronic databases (PubMed and Web of Science) were systematically searched to identify eligible studies. ${ }^{1}$ The small number of required papers could be a notable limitation of this systematic review. In our opinion, more electronic databases, including Embase, Ovid, Scopus, the Cochrane Library, and Cochrane Central Register of Controlled Trials, and several Chinese databases (CNKI (Chinese National Knowledge Infrastructure), CBM (Chinese Biology Medicine) disc, VIP, Wanfang database, etc) should be thoroughly searched to achieve a comprehensive literature retrieval. Second, the search strategy report of database and manual search protocol were not clearly described, ${ }^{1}$ which may be regarded as a flaw in the metaanalysis. Third, the publication language of selected literature was strangely limited to English, which could inevitably lead to potential language bias. ${ }^{1}$

2. With respect to quality assessment section, the investigators clarified that "A study was considered high-quality if it achieved a score of 7 or more", while a low-quality study conducted by van Gaal et $\mathrm{al}^{2}$ with a Newcastle-Ottawa quality assessment scale score of 6 was not excluded by the investigators ${ }^{1}$ (Table 2). We would like to know the possible reason for the inclusion of this study. In addition, the authors claimed that they performed this meta-analysis in accordance with the Preferred Reporting Items for Systematic Reviews and Meta-analyses (PRISMA) standardized guidelines. ${ }^{3}$ However, sensitivity analysis, a procedure which is strongly recommended in PRISMA guidelines, was not performed in this review. We take the attitude that any effort to increase the credibility of meta-analysis should be attached importance 
and suggest that the investigators could supplement this procedure.

3. It is insufficient that most pooled results in this meta-analysis were only presented in the form of text (Table 3). ${ }^{1}$ We suggest that all the forest plots should be added to make this paper more convincing and legible. Moreover, a total of seven eligible studies were ultimately included in this meta-analysis, and the observed heterogeneity among them was obvious $\left(I^{2}=88 \%\right)$. ${ }^{1}$ The subgroup analysis was further performed; however, the heterogeneity remained significant in most of the subgroups. Thus, we are wondering whether it is appropriate to conduct this meta-analysis, since the marked heterogeneity could introduce apparent bias to this review.

4. Only the overall survival was applied to show the prognostic value of IGF-1R expression in BSTS in this article. To make this meta-analysis better, we think that the correlation between IGF-1R and other important prognostic indicators, such as progression-free survival and disease-free survival, shall be added as well. Furthermore, the investigators clarified that publication bias was assessed by "Eggers' linear regression test". ${ }^{1}$ However, the statistical result ( $P$-value) of the publication bias was absent in the "Results" section. We suggest that the authors could add this data to make this meta-analysis more credible.

Admittedly, we respect the contribution of the investigators for offering us a valuable meta-analysis on the prognostic value of IGF-1R expression in BSTS. However, the results should be interpreted with caution before the aforementioned queries were answered. We hope our comments could contribute to a more accurate elaboration of the results by Liang et $\mathrm{al}^{1}$ and agree with the investigators that more standardized prospective studies with high quality are still demanded to further evaluate the prognostic value of IGF-1R in BSTS.

\section{Acknowledgments}

This work was financially supported by the National Natural Science Foundation of China (No 81372180) and by Hunan Provincial Natural Science Foundation of China (No 2015SK2023 and No 2014FJ3095).

\section{Disclosure}

The authors have no conflict of interest to disclose in this communication.

\section{References}

1. Liang J, Li B, Yuan L, et al. Prognostic value of IGF-1R expression in bone and soft tissue sarcomas: a meta-analysis. Onco Targets Ther. 2015;8:1949-1955.

2. van Gaal JC, Roeffen MH, Flucke UE, et al. Simultaneous targeting of insulin-like growth factor-1 receptor and anaplastic lymphoma kinase in embryonal and alveolar rhabdomyosarcoma: a rational choice. Eur $J$ Cancer. 2013;49(16):3462-3470.

3. Moher D, Liberati A, Tetzlaff J, et al. Preferred reporting items for systematic reviews and meta-analyses: the PRISMA statement. BMJ. 2009;339:b2535.

Dove Medical Press encourages responsible, free and frank academic debate. The content of the OncoTargets and Therapy 'letters to the editor' section does not necessarily represent the views of Dove Medical Press, its officers, agents, employees, related entities or the OncoTargets and Therapy editors. While all reasonable steps have been taken to confirm the content of each letter, Dove Medical Press accepts no liability in respect of the content of any letter, nor is it responsible for the content and accuracy of any letter to the editor.

\section{Publish your work in this journal}

OncoTargets and Therapy is an international, peer-reviewed, open access journal focusing on the pathological basis of all cancers, potential targets for therapy and treatment protocols employed to improve the management of cancer patients. The journal also focuses on the impact of management programs and new therapeutic agents and protocols on patient perspectives such as quality of life, adherence and satisfaction. The manuscript management system is completely online and includes a very quick and fair peer-review system, which is all easy to use. Visit http://www.dovepress.com/testimonials.php to read real quotes from published authors. 